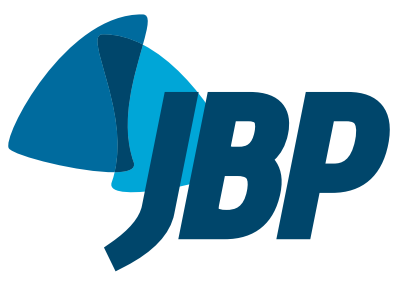

\title{
Management of COPD within the Brazilian Unified Health Care System in the state of Bahia: an analysis of real-life medication use patterns
}

\author{
Charleston Ribeiro Pinto, 1,2,3,a, Antônio Carlos Moreira Lemos 3 , b, \\ Lindemberg Assunção-Costa ${ }^{4, c}$, Aramis Tupiná de Alcântara ${ }^{5, d}$, \\ Laira Lorena Lima Yamamura ${ }^{6, e}$, Gisélia Santana Souza ${ }^{4, f}$, \\ Eduardo Martins Netto',7,g
}

1. Programa de Pós-Graduação em Medicina e Saúde, Faculdade de Medicina, Universidade Federal da Bahia, Salvador (BA) Brasil.

2. Curso de Farmácia, Departamento de Ciências e Tecnologias, Universidade Estadual do Sudoeste da Bahia, Jequié (BA) Brasil.

3. Ambulatório de Pneumologia, Complexo Hospitalar Universitário Professor Edgard Santos, Universidade Federal da Bahia, Salvador (BA) Brasil.

4. Faculdade de Farmácia, Universidade Federal da Bahia, Salvador (BA) Brasil.

5. Diretoria de Assistência Farmacêutica, Secretaria da Saúde do Estado da Bahia, Salvador (BA) Brasil.

6. Secretaria de Saúde do Município de Lauro de Freitas, Lauro de Freitas (BA) Brasil.

7. Laboratório de Pesquisa em Doenças Infecciosas, Complexo Hospitalar Universitário Professor Edgard Santos, Universidade Federal da Bahia, Salvador (BA) Brasil.

a. (D) http://orcid.org/0000-0001-9999-054X

b. (D) http://orcid.org/0000-0002-2947-1995

c. (D) http://orcid.org/0000-0002-8752-7301

d. (ID http://orcid.org/0000-0001-9392-2386

e. (iD http://orcid.org/0000-0002-1076-902X

f. (iD http://orcid.org/0000-0001-6289-4896

g. (D) http://orcid.org/0000-0003-1691-6761

Submitted: 14 November 2017

Accepted: 8 June 2018.

Study carried out in the Serviço de

Pneumologia do Complexo Hospitalar

Universitário Professor Edgard Santos,

Universidade Federal da Bahia,

Salvador (BA) Brasil.

\section{INTRODUCTION}

COPD is an important cause of morbidity and mortality worldwide. Low- and middle-income countries such as Brazil account for more than $90 \%$ of all deaths. ${ }^{(1,2)}$ Despite its significant economic, personal, and social impact, COPD remains underdiagnosed and undertreated, especially in these countries, because of obstacles posed by health care systems to its diagnosis and because of limited access to medications that are essential for treating respiratory diseases. ${ }^{(3-7)}$

\begin{abstract}
Objective: To describe COPD pharmacological treatment patterns in the state of Bahia, Brazil, and to evaluate the extent to which these patterns conform to clinical guidelines for the management of COPD. Methods: This was a cross-sectional study of 441 patients referred from the Public Health Care Network of the state of Bahia to a public referral outpatient clinic of a COPD management program of the Brazilian Unified Health Care System. Individuals with a spirometry-confirmed diagnosis of moderate to very severe COPD were included in the study. Patients were evaluated as to whether they had used any COPD medications in the last seven days. The appropriateness or inappropriateness (undertreatment or overtreatment) of the patient's pharmacological treatment was evaluated by comparing the patient's current treatment with that recommended by national and international guidelines. Results: A total of 383 individuals were included in the analysis. Approximately half of the patients (49.1\%) used long-acting bronchodilators. These patients were older and had had the disease longer. Of the sample as a whole, $63.7 \%$ and $83.0 \%$ did not receive pharmacological treatment in accordance with international and national recommendations, respectively. Inappropriateness due to undertreatment was indentified in more than half of the patients. Conclusions: Longacting bronchodilators are frequently underused in individuals with moderate to very severe COPD within the Brazilian Unified Health Care System in the state of Bahia. Most patients in our sample were treated inappropriately, and undertreatment predominated. Strategies to improve access to long-acting bronchodilators and the quality of COPD pharmacological management are required.
\end{abstract}

Keywords: Pulmonary disease, chronic obstructive/therapy; Drug therapy; Clinical protocols 
did not use bronchodilators. ${ }^{(7)}$ In Brazil, one study estimated that $83.3 \%$ of the patients diagnosed with COPD had not used any medications to treat the disease in the previous 12 months. ${ }^{(12)}$ An analysis ${ }^{(11)}$ of prior treatment of hospitalized patients with COPD revealed that approximately half of them did not use maintenance treatment in accordance with the Global Initiative for Chronic Obstructive Lung Disease (GOLD) recommendations. ${ }^{(1)}$

Despite the high burden of COPD in Brazil, to date there has been little evidence on the level of appropriateness of COPD treatment in the country, especially from the perspective of the Sistema Único de Saúde (SUS, Brazilian Unified Health Care System). Data from our study may be useful in planning initiatives to improve the quality of management of this disease. ${ }^{(13)}$

The objective of the present study was to describe COPD pharmacological treatment patterns in a population of patients treated within the SUS in the state of Bahia, Brazil, and to investigate the extent to which these patterns conform to clinical guidelines for the management of COPD.

\section{METHODS}

This was a cross-sectional study of patients previously diagnosed with COPD who were referred from the Rede de Atenção à Saúde (RAS, Public Health Care Network) of the SUS in the state of Bahia to the Referral Outpatient Clinic of a public COPD management program (Programa Respira Bahia [Breathe, Bahia Program]) of the Octávio Mangabeira Specialized Hospital, located in the city of Salvador, Brazil. The program is an initiative of the Bahia State Health Department in partnership with the Department of Pulmonology of the Federal University of Bahia Professor Edgard Santos University Hospital, located in that same city, aimed at implementing a network of care for patients with respiratory symptoms in the state of Bahia to improve the quality of clinical management of and the health care system's decision-making ability regarding respiratory diseases (tuberculosis, COPD, asthma, acute respiratory infection, and lung cancer). The program activities for COPD include medical and pharmaceutical care, with free continued dispensation of medications, which are made available by the Pharmacy Department of the Referral Outpatient Clinic. The medications provided by the program included the following: short-acting $\beta_{2}$ agonists (SABAs); and long-acting bronchodilators-long-acting muscarinic antagonists (LAMAs) or long-acting $\beta_{2}$ agonists (LABAs), alone or combined with inhaled corticosteroids (ICSs). The medications were prescribed by pulmonologists involved with the program, in accordance with a COPD patient treatment protocol established by the Bahia State Health Department on the basis of the 2010 GOLD treatment recommendations. ${ }^{(14)}$

The inclusion criteria were as follows: being a COPD patient aged $\geq 40$ years; being enrolled in the Breathe, Bahia Program between June 2011 and January 2012; having GOLD II (moderate), GOLD III (severe), or GOLD IV (very severe) $\operatorname{COPD}^{(14)}$; and having a post-bronchodilator $\mathrm{FEV}_{1} / \mathrm{FVC}$ ratio $<0.7$ and a postbronchodilator $\mathrm{FEV}_{1}<80 \%$ of predicted, as measured by spirometry. The exclusion criteria were as follows: having asthma; declining to participate in the study; and being unable to give written informed consent.

Data were collected through interviews conducted by two pharmacists and a pulmonologist, all of whom had been previously trained, during enrollment in the program. To that end, they used a structured questionnaire addressing the following: demographic variables-age, gender, and self-reported race; socioeconomic variables-number of years of schooling and per capita family income (in number of times the national minimum wage); and clinical variables-smoking status, smoking history, number of comorbidities, COPD duration (in years), spirometry results (pre- and post-bronchodilator $\mathrm{FEV}_{1}$ ), baseline dyspnea, COPD spirometric severity (moderate, severe, and very severe) based on the degree of airflow limitation, and COPD classification (risks and symptoms) into GOLD groups (A, B, C, and D). ${ }^{(14)}$ Patients were asked whether they had used any COPD medications in the past seven days. COPD medications were stratified into four classes: short-acting bronchodilators-shortacting muscarinic antagonists (SAMAs), SABAs, and their combinations; long-acting bronchodilators (LAMAs and LABAs, alone or combined with ICSs); ICSs; and methylxanthines.

Patients were classified as GOLD group A (low risk and fewer symptoms), B (low risk and more symptoms), $C$ (high risk and fewer symptoms), or D (high risk and more symptoms).(1) In addition, participants were classified as having moderate, severe, or very severe COPD, in accordance with the guidelines of the Brazilian National Ministry of Health Department of Health Policies. ${ }^{(15)}$

The appropriateness or inappropriateness (undertreatment or overtreatment) of the patient's pharmacological treatment was evaluated by comparing the patient's current treatment with that recommended by international and national guidelines. ${ }^{(1,15)}$ For both guidelines, undertreatment was defined as the complete absence of pharmacological treatment or the lack of use of recommended medications. On the basis of national guidelines, ${ }^{(15)}$ overtreatment was defined as the use of ICSs in patients with moderate COPD or the use of ICSs + long-acting bronchodilators in patients with severe to very severe COPD without recurrent exacerbations. In accordance with international guidelines, $^{(1)}$ overtreatment was defined as the use of ICS + SABA or SAMA or SABA + SAMA in patients classified as GOLD group A, the use of ICS + LABA or LAMA or LABA + LAMA in patients in GOLD group $B$, or the use of ICS + LAMA or LABA + LAMA in patients in GOLD group $C$. The sum of the proportions of undertreatment and overtreatment resulted in the proportion of inappropriate treatment. 
A COPD exacerbation was defined as an acute-onset change in baseline dyspnea, cough, and/or expectoration that is beyond normal day-to-day variations and can lead to a change in medication. ${ }^{(14)}$

Baseline dyspnea was assessed with the modified Medical Research Council (mMRC) scale, ${ }^{(16)}$ and symptom presence and absence were defined as scores $\geq 2$ and scores $<2$, respectively.

Spirometry was performed with a Koko Pneumotach spirometer (PDS Instrumentation Inc., Louisville, CO, USA) that was previously calibrated in accordance with the criteria recommended by the American Thoracic Society/European Respiratory Society. ${ }^{(17)}$ All spirometric variables were expressed as a percentage of predicted normal values for a Brazilian reference population. ${ }^{(18)}$

Data analysis was performed with the IBM SPSS Statistics software package, version 21.0 (IBM Corporation, Armonk, NY, USA). Data were presented as mean and standard deviation or as frequency and proportion. Differences in demographic, socioeconomic, and clinical variables between patients who used long-acting bronchodilators and those who did not were analyzed by the chi-square test or the Student's t-test. The level of significance was set at $p<0.05$. Medication use patterns were analyzed by GOLD group, spirometric disease severity, and mMRC dyspnea grade, with the use of the chi-square test. The chisquare test was also used to identify differences in the frequency of appropriate treatment, undertreatment, and overtreatment across spirometric disease severity categories and across GOLD groups.
The study protocol was approved by the Research Ethics Committee of the Bahia State Health Department (Protocol no. 17268313.8.0000.5030). All participating patients gave written informed consent.

\section{RESULTS}

A total of 441 patients were recruited for the study. Of those, 383 met the study's inclusion criteria and participated in the analysis (Figure 1). Most patients $(65 \%)$ resided in the city of Salvador; the rest resided in one of 40 municipalities in the state of Bahia. Of the sample as a whole, 271 patients $(70.8 \%)$ used COPD medications, approximately half of whom (49.1\%) used long-acting bronchodilators.

Most patients were male (67.9\%), had a mean age of $65.9 \pm 11.1$ years, self-reported being non-White $(92.7 \%)$, and had a family income $\leq$ one time the national minimum wage (79.6\%). Approximately $80 \%$ of the patients were symptomatic (mMRC scale scores $\geq 2$ ). Classification of COPD severity based on the degree of airflow limitation was as follows: moderate, in $24.3 \%$; severe, in $48.8 \%$; and very severe, in $26.9 \%$. Most patients were classified as GOLD group C or D (14.6\% and $70.5 \%$, respectively), which are groups at higher risk of exacerbation.

Patient general characteristics by long-acting bronchodilator use status (use vs. non-use) are presented in Table 1. Individuals who used long-acting bronchodilators were significantly older and had had the disease longer.

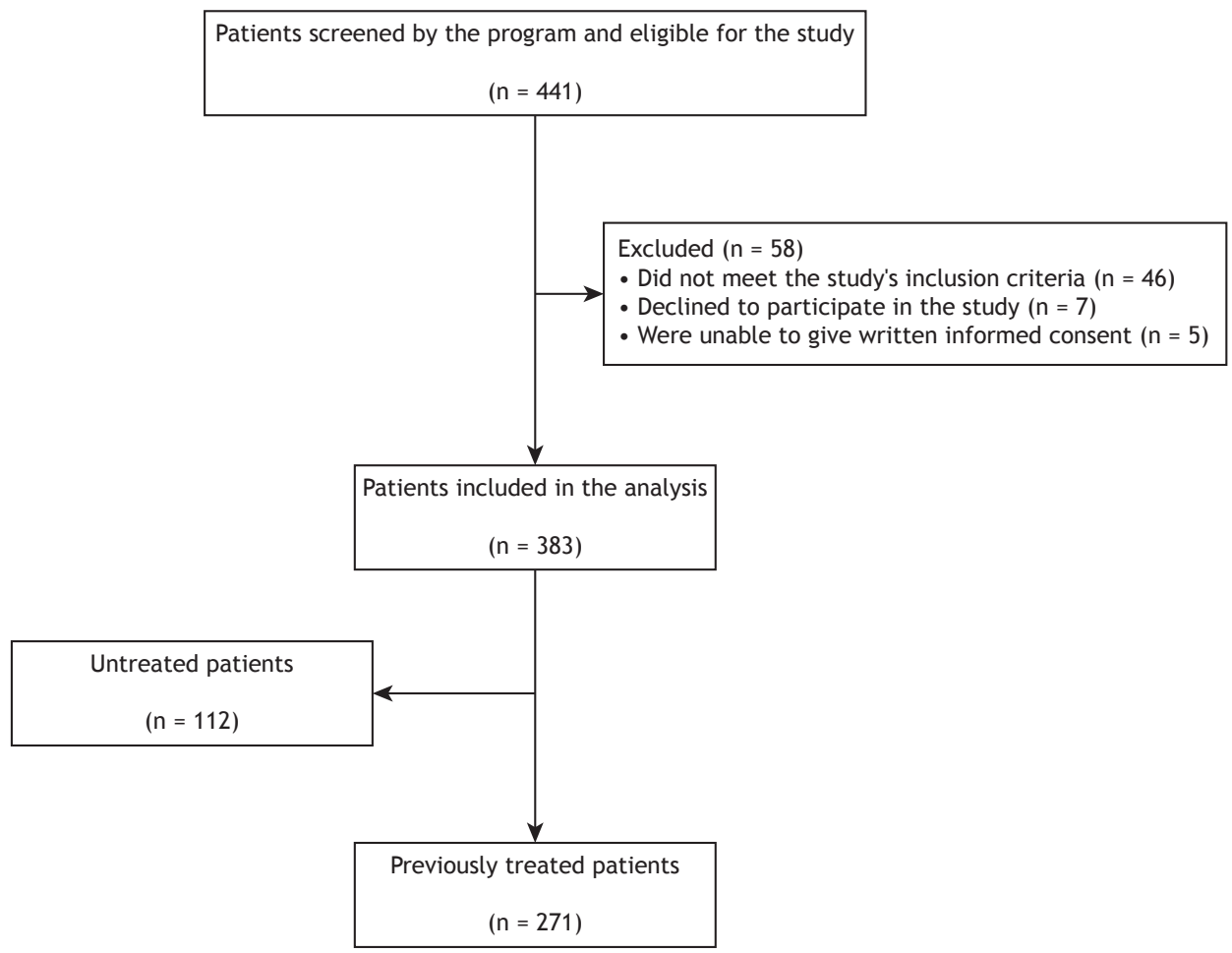

Figure 1. Flow chart of the patients in the study. 
The most commonly consumed medications were LABA, in $47.5 \%$ of the patients; ICSs, in $44.9 \%$; SABA, in $33.7 \%$; SAMA, in $9.7 \%$; LAMA, in $9.7 \%$; and methylxanthines, in $9.4 \%$. We did not identify significant differences in medication use patterns across the spirometric disease severity levels or GOLD groups (Table 2). However, for those who used SABA, consumption was higher in GOLD groups $C$ and $D$ than in GOLD groups $A$ and $B(p=0.04)$. In addition, symptomatic patients more commonly used LAMA alone or in combination with LABA or with LABA + ICS.

An assessment of the observed patterns of medication use relative to international and national recommendations ${ }^{(1,15)}$ revealed that only $139(36.3 \%)$ and $65(17.0 \%)$ of the patients received appropriate pharmacological treatment, respectively. According to those guidelines, ${ }^{(1,15)}$ the most common cause of inappropriate treatment was undertreatment, in $55.1 \%$ and $53.0 \%$ of the patients, respectively. The proportions of appropriately treated, undertreated, and overtreated patients by disease severity (based on the degree of airflow obstruction) and by GOLD group (A-D) are presented in Figures 2 and 3, respectively. The proportion of appropriately treated individuals was significantly higher among patients with severe COPD $(22.5 \%)$ than among those with moderate or very severe COPD (5.4\% and $17.5 \%$, respectively; $\mathrm{p}<0.001)$. Overtreatment was significantly more common in patients with moderate COPD (46.2\%) than in those with severe COPD $(23.5 \%)$ or very severe

Table 1. Patient general characteristics by long-acting bronchodilator use status. a

\begin{tabular}{|c|c|c|c|}
\hline \multirow[t]{2}{*}{ Variable } & \multicolumn{2}{|c|}{ Any LABD use } & \multirow[t]{2}{*}{$p^{*}$} \\
\hline & No & Yes & \\
\hline \multicolumn{4}{|l|}{ Gender } \\
\hline Male & $127(48.8)$ & $133(51.2)$ & \multirow{2}{*}{0.239} \\
\hline Female & $68(55.3)$ & $55(44.7)$ & \\
\hline Age, years & $64.1 \pm 11.4$ & $67.8 \pm 10.4$ & 0.001 \\
\hline \multicolumn{4}{|l|}{ Self-reported race } \\
\hline White & $17(60.7)$ & $11(39.3)$ & \multirow{2}{*}{0.281} \\
\hline Non-White & $178(50.1)$ & $177(49.9)$ & \\
\hline \multicolumn{4}{|l|}{ Schooling, years } \\
\hline$<9$ & $160(52.1)$ & $147(47.9)$ & \multirow{2}{*}{0.344} \\
\hline$\geq 9$ & $35(46.1)$ & $41(53.9)$ & \\
\hline \multicolumn{4}{|c|}{ Per capita family income, number of times the NMW } \\
\hline$\leq 1$ & $160(52.5)$ & $145(47.5)$ & \multirow{2}{*}{0.232} \\
\hline$>1$ & $35(44.9)$ & $43(55.1)$ & \\
\hline Smoking history, pack-years & $42.6 \pm 34.9$ & $39.4 \pm 34.5$ & 0.374 \\
\hline \multicolumn{4}{|l|}{ Smoking status } \\
\hline Never smoker & $7(50.0)$ & $7(50.0)$ & \multirow{3}{*}{0.957} \\
\hline Former smoker & $173(50.7)$ & $168(49.3)$ & \\
\hline Smoker & $15(53.6)$ & $13(46.4)$ & \\
\hline COPD duration, years & $8.7 \pm 8.3$ & $11.0 \pm 10.6$ & 0.045 \\
\hline \multicolumn{4}{|l|}{ Number of comorbidities } \\
\hline$<5$ & $185(51.7)$ & $173(48.3)$ & \multirow{2}{*}{0.259} \\
\hline$\geq 5$ & $10(40.0)$ & $15(60.0)$ & \\
\hline Pre-bronchodilator $\mathrm{FEV}_{1}, \%$ predicted & $36.51 \pm 12.26$ & $36.87 \pm 13.47$ & 0.826 \\
\hline Post-bronchodilator $\mathrm{FEV}_{1}, \%$ predicted & $39.44 \pm 13.73$ & $40.32 \pm 13.96$ & 0.623 \\
\hline \multicolumn{4}{|l|}{ mMRC dyspnea grade } \\
\hline$<2$ & $42(53.8)$ & $36(46.2)$ & \multirow{2}{*}{0.562} \\
\hline$\geq 2$ & $153(50.2)$ & $152(49.8)$ & \\
\hline \multicolumn{4}{|l|}{ Spirometric severity } \\
\hline Moderate & $45(48.4)$ & $48(51.6)$ & \multirow{3}{*}{0.853} \\
\hline Severe & 97 (51.9) & $90(48.1)$ & \\
\hline Very severe & $53(51.5)$ & $50(48.5)$ & \\
\hline \multicolumn{4}{|l|}{ GOLD group } \\
\hline A & $11(50.0)$ & $11(50.0)$ & \multirow{4}{*}{0.212} \\
\hline B & $12(34.3)$ & $23(65.7)$ & \\
\hline C & $31(55.4)$ & $25(44.6)$ & \\
\hline D & $141(52.2)$ & $129(47.8)$ & \\
\hline
\end{tabular}

LABD: long-acting bronchodilator; NMW: national minimum wage; mMRC: modified Medical Research Council; and GOLD: Global Initiative for Chronic Obstructive Lung Disease. avalues expressed as $\mathrm{n}(\%)$ or as mean \pm SD. *Student's t-test or chi-square test. 
COPD (27.2\%; $\mathrm{p}<0.001)$.GOLD groups $C$ and $D$ had a significantly higher proportion of appropriately treated COPD patients than did GOLD groups $A$ and $B(p<$ 0.001). The proportion of overtreated COPD patients was significantly higher in the lower-risk GOLD groups (A, 54.5\%; and $B, 54.3 \%$ ) than in the higher-risk GOLD groups (C, 3.6\%; and D, $0.0 \% ; \mathrm{p}<0.001$ ).

\section{DISCUSSION}

The present study has shown that $83.0 \%$ and $63.7 \%$ of the patients in our sample were treated inappropriately according to the recommendations of international and national guidelines, ${ }^{(1,15)}$ respectively. To our knowledge, this is the first large-scale study in Brazil, conducted within the SUS, evaluating the level of appropriateness of COPD pharmacological treatment relative to the recommendations of treatment guidelines. In general, the level of treatment inappropriateness identified in the present study was higher than that observed in other studies conducted in different countries, which found values ranging from $26.0 \%$ to $81.3 \% .^{(9-11,19-21)}$ This suggests differences in COPD treatment across countries and reveals that there are important gaps between the recommended treatment and the treatment provided to COPD patients within the SUS. However, comparison of results should be made with caution because of the disease severity profile of the patients involved in these studies, most of whom had moderate COPD. In addition, it should be noted that the data presented here were obtained in the setting of the SUS RAS; therefore, the data involved individuals referred from primary, secondary, and tertiary health care settings, unlike most previous studies, which were conducted at referral outpatient clinics. The high level of treatment inappropriateness observed in our study was greater than that previously reported by Giacomelli et al. ${ }^{(11)}$ in a study conducted in Brazil that analyzed the appropriateness of pharmacological maintenance treatment in 50 COPD patients prior to their hospitalization. The authors showed that, relative

Table 2. Distribution of COPD medication use patterns by dyspnea grade. spirometric disease severity. and Global Initiative for Chronic Obstructive Lung Disease (GOLD) group. ${ }^{a}$

\begin{tabular}{|c|c|c|c|c|c|c|c|c|c|}
\hline Variable & $\begin{array}{l}\text { Any } \\
\text { SABA } \\
\text { use }\end{array}$ & $\begin{array}{l}\text { Any } \\
\text { SAMA } \\
\text { use }\end{array}$ & $\begin{array}{l}\text { Any } \\
\text { LABA } \\
\text { use }\end{array}$ & $\begin{array}{l}\text { Any } \\
\text { LAMA } \\
\text { use }\end{array}$ & $\begin{array}{c}\text { Any ICS } \\
\text { use }\end{array}$ & $\begin{array}{c}\text { Any } \\
\text { methylxan- } \\
\text { thine use }\end{array}$ & $\begin{array}{c}\text { Any } \\
\text { LABA + } \\
\text { ICS use }\end{array}$ & $\begin{array}{c}\text { Any } \\
\text { LABA + } \\
\text { LAMA } \\
\text { use }\end{array}$ & $\begin{array}{c}\text { Any } \\
\text { LABA + } \\
\text { LAMA + } \\
\text { Cl use }\end{array}$ \\
\hline $\begin{array}{l}\text { mMRC dyspnea } \\
\text { grade }\end{array}$ & $p=0.733$ & $p=0.818$ & $p=0.787$ & $p=0.017$ & $p=0.605$ & $p=0.311$ & $p=0.683$ & $p=0.038$ & $p=0.045$ \\
\hline$<2$ & 32.1 & 9 & 42.6 & 2.6 & 42.3 & 6.4 & 39.7 & 2.6 & 2.6 \\
\hline$\geq 2$ & 24.1 & 9.8 & 47.9 & 11.5 & 45.6 & 10.2 & 42.3 & 9.8 & 9.5 \\
\hline COPD severity & $p=0.071$ & $p=0.170$ & $p=0.655$ & $p=0.493$ & $p=0.429$ & $p=0.075$ & $p=0.599$ & $p=0.545$ & $p=0.697$ \\
\hline Moderate & 24.7 & 5.4 & 51.6 & 8.6 & 80.5 & 9.7 & 46.2 & 8.6 & 8.6 \\
\hline Severe & 38.5 & 12.3 & 46.5 & 8.6 & 43.9 & 6.4 & 40.6 & 7.0 & 7.0 \\
\hline Very severe & 33 & 8.7 & 45.6 & 12.6 & 41.7 & 14.6 & 39.8 & 10.7 & 9.7 \\
\hline GOLD group & $p=0.040$ & $p=0.302$ & $p=0.151$ & $p=0.117$ & $p=0.117$ & $p=0.585$ & $p=0.281$ & $p=0.196$ & $p=0.213$ \\
\hline$A$ & 13.6 & 0 & 50 & 0 & 59.1 & 4.5 & 50 & 0.0 & 0.0 \\
\hline B & 20 & 5.7 & 65.7 & 11.4 & 57.1 & 14.3 & 54.3 & 11.4 & 11.4 \\
\hline$C$ & 39.3 & 12.5 & 44.6 & 3.6 & 35.7 & 7.1 & 35.7 & 3.6 & 3.6 \\
\hline$D$ & 35.9 & 10.4 & 45.6 & 11.5 & 44.1 & 9.1 & 40.7 & 9.6 & 9.3 \\
\hline
\end{tabular}

mMRC: modified Medical Research Council; SABA: short-acting $\beta_{2}$ agonist; SAMA: short-acting muscarinic antagonist; LABA: long-acting $\beta_{2}$-agonist; LAMA: long-acting muscarinic antagonist; and ICS: inhaled corticosteroid. alues expressed as $n(\%)$.

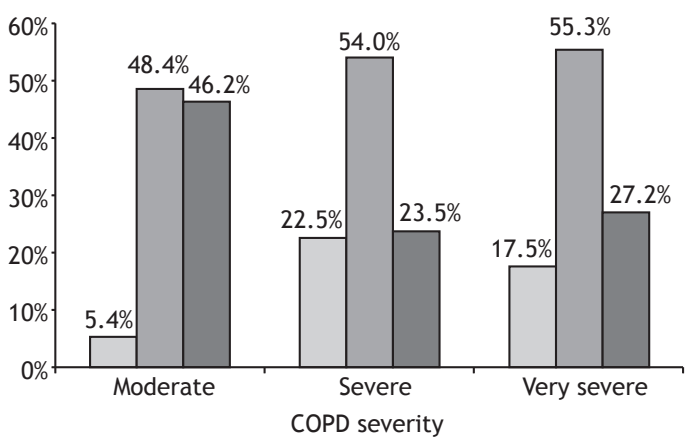

$\square$ Appropriate treatment $\square$ Undertreatment $\square$ Overtreatment

Figure 2. Distribution of individuals appropriately treated, undertreated, or overtreated for COPD, by disease severity as defined by national guidelines. ${ }^{(15)}$

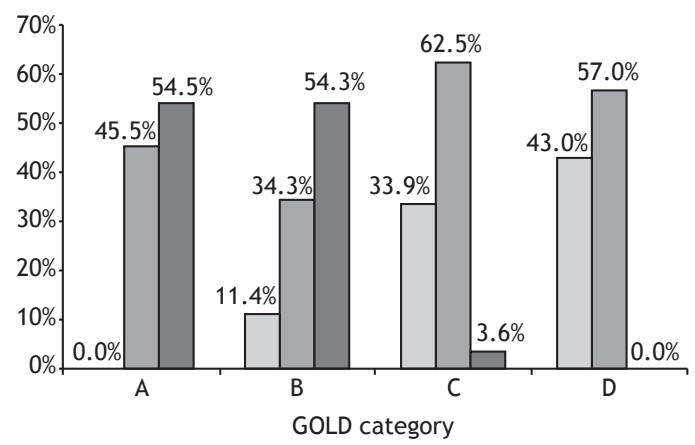

$\square$ Appropriate treatment $\square$ Undertreatment $\square$ Overtreatment

Figure 3. Distribution of individuals appropriately treated, undertreated, or overtreated for COPD, by Global Initiative for Chronic Obstructive Lung Disease (GOLD) category. ${ }^{(1)}$ 
to what is recommended by the same international and national guidelines, ${ }^{(1,15)}$ treatment was inappropriate in $50 \%$ and $74 \%$ of the patients, respectively. Our findings are a cause for concern, given that COPD is a highly prevalent disease with a substantial economic impact on the Brazilian health care system. In addition, lack of compliance with treatment guidelines for COPD is known to be associated with higher total health care costs. ${ }^{(22)}$

In Brazil, factors such as a low level of education, low income, non-use of oxygen therapy, and lack of influenza vaccination have been associated with inappropriate COPD treatment.(11) Other factors that should be taken into account include low adherence to treatment guidelines for COPD and poor physician knowledge of these guidelines. A survey conducted in 2013 in 12 countries, including Brazil, revealed that there are gaps in the application of treatment guidelines for COPD by physicians in Brazil.(23) An international survey involving some countries showed that $34 \%$ of general practitioners in Brazil did not use treatment guidelines for COPD for the management of their patients. ${ }^{(24)}$ In addition, other barriers, such as limited access to health care and medications within the SUS, may be considered. ${ }^{(25)}$

Long-acting bronchodilators are guideline recommended for the management of symptomatic patients with COPD. ${ }^{(1,26)}$ The benefits of these medications on quality of life, dyspnea, exacerbations, and lung function are well documented in the literature. (26) However, as in our study, evidence has shown that long-acting bronchodilators have been underused in clinical practice in different countries and settings. ${ }^{(11,27-29)}$ We found that approximately half of the patients used long-acting bronchodilators, with consumption being higher in individuals who were older and who had had the disease longer. This value is lower than that found in two recent studies, one conducted in Brazil and one conducted in primary care in the United Kingdom, in which the reported proportion of use of these medications was $64 \%$ and $77 \%$, respectively. ${ }^{(11,28)}$ However, it was higher than that found in a multinational, non-interventional study that evaluated bronchodilator use among COPD patients recruited from primary care settings in four countries in Latin America (Argentina, Colombia, Venezuela, and Uruguay). (29) The authors showed that only $30.9 \%$ of the patients who had been previously diagnosed with the disease used long-acting bronchodilators, 9.8\% of whom as monotherapy and $21.1 \%$ of whom as combination therapy with an ICS.

The present study showed that, relative to the GOLD guidelines, ${ }^{(1)} 211$ patients (55.1\%) were undertreated. Of those, 112 (53.1\%) did not use any medications to treat the disease. This value contrasts with that reported by a study conducted in Brazil in which inappropriateness due to undertreatment was estimated to be $38 \%$. ${ }^{(11)}$ In another study, Nascimento et al. ${ }^{(12)}$ showed that $50 \%$ of the patients who had been previously diagnosed with COPD received some pharmacological treatment for the disease. This observed difference can be explained by the different settings and, especially, by the eligibility criteria and patient recruitment strategies used in the different studies.

It should be noted that access to medications to treat chronic diseases within the SUS varies across the different regions of Brazil. ${ }^{(30,31)}$ In addition, an analysis of data from the Brazilian National Survey on Access to, Use of, and Promotion of Rational Use of Medications, conducted between 2013 and 2014, revealed a high rate of patients' purchase of medications that act on the respiratory system, such as agents against obstructive airway diaseses, with their own resources, suggesting that barriers to cost-free access to this group of medications have yet to be overcome. (31) Furthermore, it is known that medications such as LAMAs are not available within the SUS, with access to them being restricted to states that have their own policies regarding the funding of these medications, such as the state of São Paulo. ${ }^{(32,33)}$ Therefore, we cannot rule out the hypothesis that, for states with limited access to LAMAs, undertreatment is even higher.

Overtreatment as a result of inappropriate ICS use was identified in more than half of the individuals in GOLD groups A and B (in 54.5\% and $54.3 \%$, respectively), as well as in $46.2 \%$ of the patients with moderate COPD. Although ICS use is limited to specific indications, ICSs have been widely prescribed in clinical practice to individuals who are unlikely to benefit from their use. ${ }^{(9,10,28,34)}$ Another concern related to ICS use in COPD is safety issues, especially because the use of these medications is associated with an increased risk of pneumonia. ${ }^{(35)}$ Recently, some researchers reviewing data from large clinical trials have recommended withdrawal of ICSs from the treatment regimen of patients for whom these medications are not indicated, with maintenance of appropriate bronchodilator therapy. ${ }^{(36)}$ It is likely that the frequency of overtreatment among individuals classified as GOLD A reported here is underestimated, since the study's inclusion criteria, which restricted the sample to patients with moderate to very severe COPD, favored the selection of a limited sample in terms of the proportion of GOLD A patients.

The present study has some limitations that should be considered in the interpretation of our results. The major limitation of this study was that the patients were not randomly selected, generating a potential selection bias. Therefore, we cannot rule out the hypothesis that the patients evaluated do not represent the whole population of COPD patients commonly treated within the RAS in the state of Bahia. However, our results reflect a more heterogeneous real-world population, representative of clinical practice. In addition, we cannot disregard the possibility that our findings do not reflect the current status of COPD treatment in Brazil, since, in 2013, the Brazilian National Ministry of Health established a dedicated clinical protocol and dedicated treatment guidelines for COPD, ${ }^{(32)}$ thus enabling new medications to be incorporated into and dispensed at no charge within the SUS. However, our findings can 
be used as historical control for future studies that will enable the monitoring of access to and use of COPD medications in clinical practice.

There is a need for studies evaluating the factors associated with inappropriate COPD treatment and the barriers to physician adherence to treatment guidelines for COPD in clinical practice within the SUS. In addition, further studies are needed to evaluate the impact of the implementation of the clinical protocol and treatment guidelines for COPD $^{(32)}$ mentioned above on the quality of COPD management within the SUS in different settings.

In conclusion, we found that long-acting bronchodilators are frequently underused for the treatment of COPD within the SUS in the state of Bahia. Furthermore, we observed a high frequency of inappropriate treatment, especially undertreatment, revealing important gaps between guideline recommendations for COPD management and clinical practice. Therefore, it is necessary to implement strategies for dissemination of treatment guidelines for COPD among physicians working within the RAS. However, COPD management programs based on multidisciplinary care and free continued access to maintenance treatment can be considered as an alternative for improving the quality of COPD management within the SUS.

\section{ACKNOWLEDGMENTS}

We thank the teams at the Octávio Mangabeira Specialized Hospital Breathe, Bahia Program, the Department of Pulmonology of the Federal University of Bahia Professor Edgard Santos University Hospital, and the Bahia State Health Department Pharmaceutical Care Board.

\section{REFERENCES}

1. Global Initiative for Chronic Obstructive Lung Disease - GOLD [homepage on the Internet]. Bethesda: Global Initiative for Chronic Obstructive Lung Disease [cited 2011 Mar 22]. Global Strategy for the Diagnosis, Management, and Prevention of COPD - Revised 2011. [Adobe Acrobat document, 90p.]. Available from: http://www. goldcopd.org

2. World Health Organization [homepage on the Internet]. Geneva: World Health Organization; 2014 [cited 2016 Nov 2]. Burden of COPD Available from: http://www.who.int/respiratory/copd/burden/en/

3. Mortimer K, Cuevas L, Squire B, Thomson R, Tolhurst R. Improving access to effective care for people with chronic respiratory symptoms in low and middle income countries. BMC Proc. 2015;9(Suppl 10):S3. https://doi.org/10.1186/1753-6561-9-S10-S3

4. Fletcher MJ, Upton J, Taylor-Fishwick J, Buist SA, Jenkins C, Hutton $J$, et al. COPD uncovered: an international survey on the impact of chronic obstructive pulmonary disease [COPD] on a working age population. BMC Public Health. 2011;11:612. https://doi. org/10.1186/1471-2458-11-612

5. Bazargani $Y T$, de Boer A, Leufkens HG, Mantel-Teeuwisse AK. Essential medicines for COPD and asthma in low and middle-income countries. Thorax. 2014;69(12):1149-51. https://doi.org/10.1136/ thoraxjnl-2014-205249

6. Casas Herrera A, Montes de Oca M, López Varela MV, Aguirre C, Schiavi E, Jardim JR, et al. COPD Underdiagnosis and Misdiagnosis in a High-Risk Primary Care Population in Four Latin American Countries. A Key to Enhance Disease Diagnosis: The PUMA Study. PloS One. 2016;11(4):e0152266. https://doi.org/10.1371/journal. pone. 0152266

7. Montes de Oca M, Lopez Varela MV, Jardim J, Stirvulov R, Surmont F. Bronchodilator treatment for COPD in primary care of four Latin America countries: The multinational, cross-sectional, noninterventional PUMA study. Pulm Pharmacol Ther. 2016;38:10-6. https://doi.org/10.1016/j.pupt.2016.04.002

8. Miravitlles $M$, Vogelmeier $C$, Roche $N$, Halpin D, Cardoso J, Chuchalin $A G$, et al. A review of national guidelines for management of COPD in Europe. Eur Respir J. 2016;47(2):625-37. https://doi. org/10.1183/13993003.01170-2015

9. Sen E, Guclu SZ, Kibar I, Ocal U, Yilmaz V, Celik O, et al. Adherence to GOLD guideline treatment recommendations among pulmonologists in Turkey. Int J Chron Obstruct Pulmon Dis. 2015;10:2657-63. https:// doi.org/10.2147/COPD.S85324

10. Corrado A, Rossi A. How far is real life from COPD therapy guidelines? An Italian observational study. Respir Med. 2012;106(7):989-97 https://doi.org/10.1016/j.rmed.2012.03.008

11. Giacomelli IL, Steidle LJ, Moreira FF, Meyer IV, Souza RG, Pincelli MP. Hospitalized patients with COPD: analysis of prior treatment J Bras Pneumol. 2014;40(3):229-37. https://doi.org/10.1590/S180637132014000300005

12. Nascimento OA, Camelier A, Rosa FW, Menezes AM, PérezPadilla R, Jardim JR, et al. Chronic obstructive pulmonary disease is underdiagnosed and undertreated in Sao Paulo (Brazil): results of the

PLATINO study. Braz J Med Biol Res. 2007;40(7):887-95. https://doi. org/10.1590/S0100-879X2006005000133

13. Milchak JL, Carter BL, James PA, Ardery G. Measuring adherence to practice guidelines for the management of hypertension: an evaluation of the literature. Hypertension. 2004;44(5):602-8. https:// doi.org/10.1161/01.HYP.0000144100.29945.5e

14. Global Initiative for Chronic Obstructive Lung Disease - GOLD [homepage on the Internet]. Bethesda: Global Initiative for Chronic Obstructive Lung Disease [cited 2010 Nov 12]. Global Strategy for the Diagnosis, Management, and Prevention of COPD - Revised 2010. [Adobe Acrobat document, 117p.]. Available from: http://www. goldcopd.org

15. Brasil. Ministério da Saúde. Secretaria de Políticas de Saúde. Departamento de Atenção Básica. Doenças respiratórias crônicas. Cadernos de Atenção Básica no. 25. Brasília: Ministério da Saúde 2010.

16. Kovelis D, Segretti NO, Probst VS, Lareau SC, Brunetto AF, Pitta F. Validation of the Modified Pulmonary Functional Status and Dyspnea Questionnaire and the Medical Research Council scale for use in Brazilian patients with chronic obstructive pulmonary disease. J Bras Pneumol. 2008;34(12):1008-18. https://doi.org/10.1590/S180637132008001200005

17. Miller MR, Hankinson J, Brusasco V, Burgos F, Casaburi R, Coates A et al. Standardisation of spirometry. Eur Respir J. 2005;26(2):319-38. https://doi.org/10.1183/09031936.05.00034805

18. Freitas CG, Pereira CA, Viegas CA. Inspiratory capacity, exercise limitation, markers of severity, and prognostic factors in chronic obstructive pulmonary disease. J Bras Pneumol. 2007;33(4):389-96. https://doi.org/10.1590/S1806-37132007000400007

19. Sharif R, Cuevas CR, Wang Y, Arora M, Sharma G. Guideline adherence in management of stable chronic obstructive pulmonary disease. Respir Med. 2013;107(7):1046-52. https://doi.org/10.1016/i rmed.2013.04.001

20. Price L, Billups SJ, Rice MA, Hartsfield C. Investigation of barriers to clinical practice guideline-recommended pharmacotherapy in the treatment of COPD. Pharm Pract (Granada). 2007;5(2):74-7. https:// doi.org/10.4321/S1886-36552007000200004

21. Foda HD, Brehm A, Goldsteen K, Edelman NH. Inverse relationship between nonadherence to original GOLD treatment guidelines and exacerbations of COPD. Int $\mathrm{J}$ Chron Obstruct Pulmon Dis. 2017;12:209-14. https://doi.org/10.2147/COPD.S119507

22. Miravitlles M, Sicras A, Crespo C, Cuesta M, Brosa M, Galera $J$, et al. Costs of chronic obstructive pulmonary disease in relation to compliance with guidelines: a study in the primary care setting. Ther Adv Respir Dis. 2013;7(3):139-50. https://doi. org/10.1177/1753465813484080

23. Davis KJ, Landis SH, Oh YM, Mannino DM, Han MK, van de Molen T, et al. Continuing to Confront COPD International Physician Survey: physician knowledge and application of COPD management guidelines in 12 countries. Int $\mathrm{J}$ Chron Obstruct Pulmon Dis. 2015;10:39-55. https://doi.org/10.2147/COPD.S70162 
24. Aisanov Z, Bai C, Bauerle O, Colodenco FD, Feldman C, Hashimoto $\mathrm{S}$, et al. Primary care physician perceptions on the diagnosis and management of chronic obstructive pulmonary disease in diverse regions of the world. Int J Chron Obstruct Pulmon Dis. 2012;7:27182. https://doi.org/10.2147/COPD.S28059

25. Boing AC, Bertoldi AD, Boing AF, Bastos JL, Peres KG. Access to medicines in the public sector: analysis of users of the Brazilian Unified National Health System [Article in Portuguese]. Cad Saude Publica. 2013;29(4):691-701. https://doi.org/10.1590/S0102 311X2013000800007

26. Asociación Latinoamericana de Tórax (ALAT) [homepage on the Internet]. Montevideo: ALAT [cited 2017 May 1]. Guía Latinoamericana de EPOC - 2014 Basada en Evidencia. https://www. alatorax.org/formacion-profesional/respirar-newsletter-alat/guialatinoamericana-de-epoc-2014-basada-en-evidencia-latinepoc-2014

27. Ford ES, Mannino DM, Giles WH, Wheaton AG, Liu Y, Croft JB. Prescription practices for chronic obstructive pulmonary disease: findings from the national ambulatory medical care survey 19992010. COPD. 2014;11(3):247-55. https://doi.org/10.3109/15412555. 2013.840570

28. Price D, West D, Brusselle G, Gruffydd-Jones K, Jones R, Miravitlles $M$, et al. Management of COPD in the UK primary-care setting: an analysis of real-life prescribing patterns. Int J Chron Obstruct Pulmon Dis. 2014;9:889-904. https://doi.org/10.2147/COPD.S62750

29. López Varela MV, Montes de Oca M, Rey A, Casas A, Stirbulov R, Di Boscio V, et al. Development of a simple screening tool for opportunistic COPD case finding in primary care in Latin America: The PUMA study. Respirology. 2016;21(7):1227-34. https://doi org/10.1111/resp.12834

30. Tavares NU, Luiza VL, Oliveira MA, Costa KS, Mengue SS, Arrais
PS, et al. Free access to medicines for the treatment of chronic diseases in Brazil. Rev Saude Publica. 2016:50(suppl 2):7s. https:// doi.org/10.1590/s1518-8787.2016050006118

31. Oliveira MA, Luiza VL, Tavares NU, Mengue SS, Arrais PS, Farias $M R$, et al. Access to medicines for chronic diseases in Brazil: a multidimensional approach. Rev Saude Publica. 2016;50(suppl 2):6s https://doi.org/10.1590/s1518-8787.2016050006161

32. Portal da Saúde [homepage on the Internet]. Brasília: Ministério da Saúde [cited 2017 Mar 17]. Protocolo clínico e diretrizes terapêuticas doença pulmonar obstrutiva crônica. Available from: http://portal.saude.gov.br/portal/saude/profissional/visualizar_texto. cfm?idtxt=35115

33. Portal da Secretaria de Estado da Saúde do Governo de São Paulo [homepage on the Internet]. São Paulo: Secretaria de Estado da Saúde [cited 2017 Mar 17]. Resolução SS no. 278; 2007 Jul 26 [Adobe Acrobat document, 12p.]. Available from: http://www.saude.sp.gov $\mathrm{br} /$ resources/ses/perfil/gestor/assistencia-farmaceutica/protocolos e-normas-tecnicas-estaduais/resolucao_ss_278_26_07_15_dpoc.pdf

34. Garcia Garcia S, Carazo Fernández L, Juan García J, Naveiro Rilo JC Chronic obstructive pulmonary disease in real life. LEONPOC study [Article in Spanish]. Aten Primaria. 2017;49(10):603-610. https://doi. org/10.1016/j.aprim.2017.01.002

35. Kew KM, Seniukovich A. Inhaled steroids and risk of pneumonia for chronic obstructive pulmonary disease. Cochrane Database Syst Rev. 2014(3):CD010115. https://doi.org/10.1002/14651858. CD010115.pub2

36. Yawn BP, Suissa S, Rossi A. Appropriate use of inhaled corticosteroids in COPD: the candidates for safe withdrawal. NPJ Prim Care Respir Med. 2016;26:16068. https://doi.org/10.1038/npjpcrm.2016.68 